\title{
Comparison of Ramosetron with Palonosetron for Prevention of Postoperative Nausea and Vomiting in Patients Receiving Opioid-Based Intravenous Patient-Controlled Analgesia after Gynecological Laparoscopy
}

\author{
Eun Jin Ahn, ${ }^{1}$ Geun Joo Choi, ${ }^{2}$ Hyun Kang, ${ }^{2}$ Chong Wha Baek, ${ }^{2}$ \\ Yong Hun Jung, ${ }^{2}$ and Young Cheol Woo ${ }^{2}$ \\ ${ }^{1}$ Department of Anesthesiology and Pain Medicine, Inje University Seoul Paik Hospital, Seoul, Republic of Korea \\ ${ }^{2}$ Department of Anesthesiology and Pain Medicine, Chung-Ang University College of Medicine, Seoul, Republic of Korea
}

Correspondence should be addressed to Hyun Kang; roman00@naver.com

Received 24 October 2016; Revised 6 February 2017; Accepted 14 February 2017; Published 5 March 2017

Academic Editor: Andrea Tinelli

Copyright (C) 2017 Eun Jin Ahn et al. This is an open access article distributed under the Creative Commons Attribution License, which permits unrestricted use, distribution, and reproduction in any medium, provided the original work is properly cited.

\begin{abstract}
We aimed to compare the effects of ramosetron and palonosetron in the prevention of postoperative nausea and vomiting (PONV) in patients that received opioid-based intravenous patient-controlled analgesia (IV-PCA) after gynecological laparoscopy. We reviewed the electronic medical records of 755 adults. Patients were classified into two groups, ramosetron (group $\mathrm{R}, n=589$ ) versus palonosetron (group $\mathrm{P}, n=166$ ). Based on their confounding factors, 152 subjects in each group were selected after the implementation of propensity score matching. The overall incidence of PONV at postoperative day (POD) 0 was lower in group R compared to group $\mathrm{P}(26.9 \%$ versus $36.8 \% ; \mathrm{P}=0.043)$. The severity of nausea was lower in group $\mathrm{R}$ than in group $\mathrm{P}$ on postoperative day (POD) $0(P=0.012)$. Also, the complete responder proportion of patients was significantly higher in group $\mathrm{R}$ compared to that in group $\mathrm{P}$ on POD $0(P=0.043)$. In conclusion, ramosetron showed a greater efficacy in the prevention of postoperative nausea at POD 0 compared to palonosetron in patients after gynecological laparoscopy.
\end{abstract}

\section{Introduction}

Postoperative nausea and vomiting (PONV) is an unpleasant and distressing complication after anesthesia and surgery [1] which can prolong the hospital stay, increase healthcare costs, and decrease patient satisfaction [2]. Notably, the incidence of PONV after gynecological laparoscopy is reported to be nearly $80 \%$ [3]. PONV may also be induced by opioid analgesics, which are widely used for patient-controlled analgesia (PCA) for pain control during the early postoperative phase. Therefore, $\mathrm{PONV}$ after gynecological laparoscopy is an important clinical problem to be solved.

Among numerous antiemetics which have been studied to prevent and treat PONV, selective serotonin 5-hydroxytryptamine type 3 (5-HT3) receptor antagonists have shown efficacy in the prophylaxis and treatment of PONV [4]. Ramosetron and palonosetron are recent developments in selective 5-HT3 receptor antagonists. Ramosetron is a 5HT3 antagonist, which exhibits higher receptor affinity and a slower dissociation rate compared to older agents in its class $[5,6]$. Palonosetron is a second-generation 5-HT3 receptor antagonist with an even higher binding affinity and a prolonged half-life (mean $40 \mathrm{~h}$ ) [7].

The aim of this retrospective study was to compare the efficacy of ramosetron and palonosetron in the prevention of PONV in patients that received opioid-based IV-PCA after gynecological laparoscopy.

\section{Materials and Methods}

2.1. Study Design. After Institutional Review Board approval (C2016048 [1791]), we reviewed the medical records of 826 adults that received fentanyl-based IV-PCA after gynecological laparoscopy at Chung-Ang University Hospital between 
January 1, 2010, and December 31, 2016. Patient information was correctly anonymized and identified prior to analysis. Informed consent was waived for this study as it was not required. Only patients who were administered a single prophylactic antiemetic with a 5-HT3 receptor antagonist postoperatively were included in this study. We classified the patients into two groups (group $\mathrm{R}=$ ramosetron; group $\mathrm{P}=$ palonosetron), based on the use of antiemetics. The patients were excluded if reoperations were performed or more than one antiemetic was administered.

In our institution, standardized IV-PCA protocol of the department of anesthesiology and pain medicine was applied to all patients. The correct dosages of fentanyl, ketorolac, or nefopam were established according to the department of surgery's concerns and the expected intensity of pain (mild, moderate, or severe) after each type of surgery. For laparoscopic gynecologic minor surgery in which mild postoperative pain was expected, fentanyl $15 \mathrm{mcg} / \mathrm{kg}$, ketorolac $180 \mathrm{mg}$ (or nefopam $120 \mathrm{mg}$ ), and antiemetics (ramosetron $0.3 \mathrm{mg}$ or palonosetron $0.25 \mathrm{mg}$ ) were added to normal saline to make a $100 \mathrm{cc}$ solution. The preset continuous infusion rate of IV-PCA was $1 \mathrm{cc} / \mathrm{hr}$, bolus dose $1 \mathrm{cc}$, and a lockout interval 15 minutes. For laparoscopic gynecologic major surgery in which moderate or severe postoperative pain was expected, fentanyl $25 \mathrm{mcg} / \mathrm{kg}$, ketorolac $180 \mathrm{mg}$ (or nefopam $120 \mathrm{mg}$ ), and antiemetics (ramosetron $0.3 \mathrm{mg}$ or palonosetron $0.25 \mathrm{mg}$ ) were added to a normal saline to make a $100 \mathrm{cc}$ solution. The setting of IV-PCA was same as minor surgery. PCA was started just after induction of anesthesia and ramosetron $0.3 \mathrm{mg}$ or palonosetron $0.25 \mathrm{mg}$ was administered just before end of surgery.

2.2. Data Collection. Relationships between demographic and perioperative variables and the factors of PONV were noted. Age, height, weight, history of smoking, PONV, type of anesthetic used (Desflurane versus Sevoflurane), use of premedication, $\mathrm{N}_{2} \mathrm{O}$, and remifentanil, operation time, dose of analgesics used in PCA, and the use of Acupan ${ }^{\circledR}$ were factors involved in the collection of data. As postoperative variables, dizziness, headache, and the amount of vomiting were measured. Additional variables included the potential requirement of rescue antiemetics and CR (complete responder) status. Complete response was defined as "the absence of nausea and vomiting and non-requirement of antiemetic medication."

The nurse, dedicated to the management of patients with IV-PCA, evaluated the severity of pain using a 10-point visual analogue scale (VAS) and the severity of nausea using a numerical rating scale (none $=0$; mild $=1$; moderate $=2$; severe $=3$; worst imaginable $=4$ ). All of the aforementioned variables were measured on POD 0 and POD 1.

The nurse only undertook tasks related to IV-PCA, and she made the rounds at least once a day to investigate issues related to IV-PCA, including pain and PONV. She had 5 years' clinical experience, and she collected data after being trained in the standardized protocols of pain and PONV investigation.
The primary endpoint was the overall incidence of PONV at $\mathrm{POD} 0$. The complete responders were also calculated by the overall incidence of PONV. The severity of nausea and requirement of rescue antiemetics were secondary outcomes in this study.

2.3. Statistics. Propensity score matching was performed to match patients from each group in a 1:1 ratio and reduce potential confounding variables [8]. Given that this was a retrospective cohort study and not a randomized trial, it was necessary to achieve comparability of the ramosetron group and palonosetron group with regard to potential confounding variables by nonrandom assignment or unbalanced covariates. The propensity score was calculated by logistic regression analysis using the following covariates: age, height, weight, history of smoking, PONV, type of anesthetic used (Desflurane versus Sevoflurane), use of premedication, $\mathrm{N}_{2} \mathrm{O}$, and remifentanil, operation time, dose of analgesics used in PCA, and the use of Acupan [9]. After calculating the propensity scores, we chose the nearest available match in order to pair each participant between the groups based on the propensity score similarities. To assess the achieved balance between the matched groups, we tested for the standardized differences for each baseline covariate. Standardized difference is the difference in the means between the two groups expressed in units of standard deviation [10]. A value of less than $20 \%$ is considered to indicate an adequate balance and, therefore, good comparability between the groups.

Before matching, baseline demographics and clinical characteristics were summarized using descriptive statistics. For continuous variables, data were presented as the meanstandard deviation, and groups were compared using the unpaired $t$-test. The descriptive variables were analyzed by either a Chi-square test or Fisher's exact test, as determined appropriate.

Propensity matched continuous variables are shown as the mean-standard deviation and categorical variables are shown as absolute numbers (percentages). Statistical differences between the groups were tested with independent $t$ tests and McNemar's test. A $p$ value $<0.05$ was considered statistically significant. All statistical analyses were performed using the SPSS software suite (IBM Corp., Armonk, NY, USA).

\section{Results}

The basic demographics and clinical characteristics of the patient population are detailed in Table 1. Among 826 adults that received fentanyl-based IV-PCA after laparoscopic gynecological surgery at Chung-Ang University Hospital between January 1, 2010, and December 31, 2016, 71 patients were excluded from our study due to missing data $(n=39)$, reoperation $(n=1)$, or the use of more than one antiemetic $(n=31)$. Therefore, a total of 755 patients were included in this study, with 589 in group R and 166 in group P (Figure 1).

3.1. Ramosetron versus Palonosetron in the Overall Series. Of 14 individual and composite predictors of confounding 


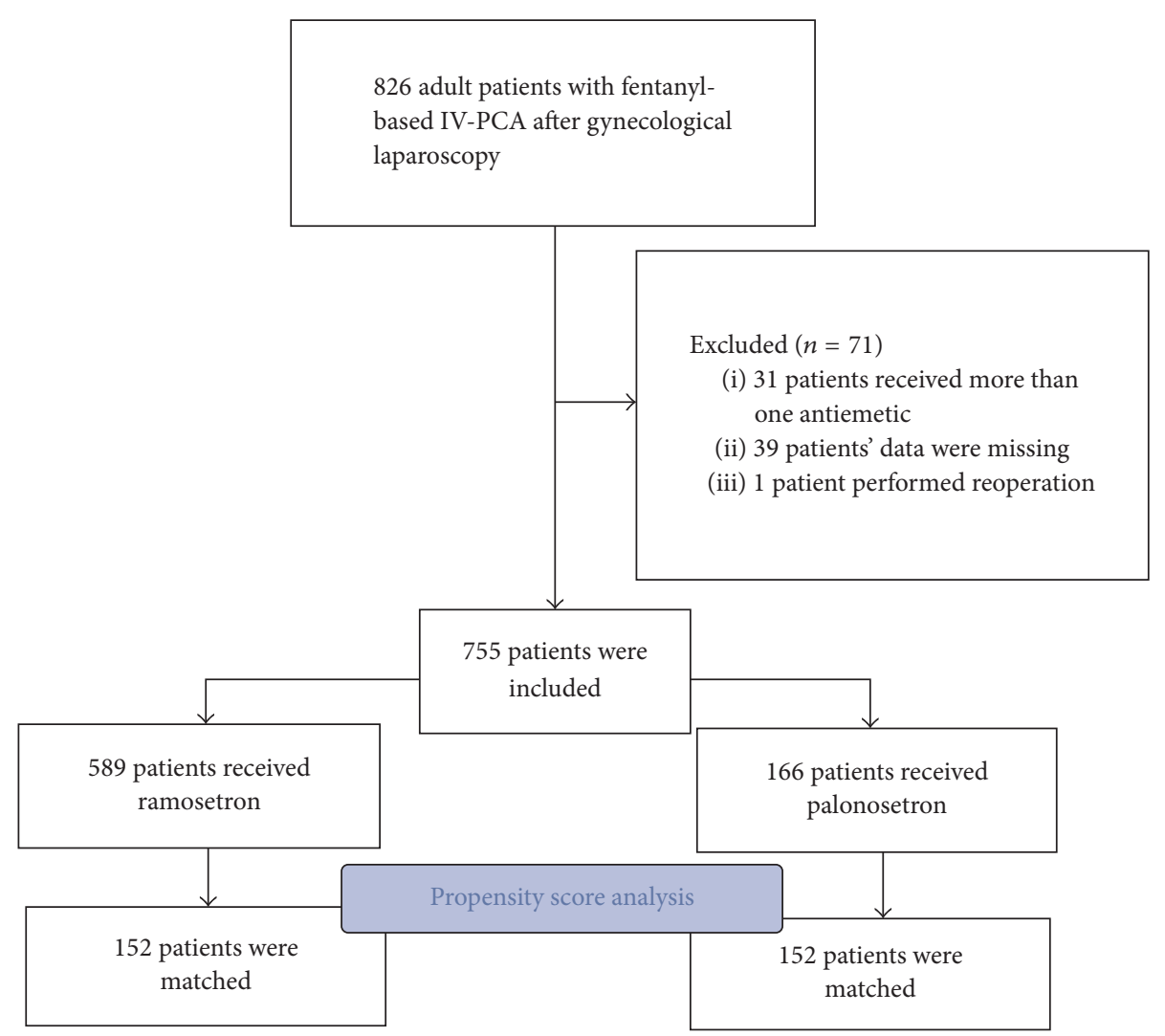

FIGURE 1: Flow diagram.

variables, 5 had poor standardized difference scores prior to the propensity score matching. Compared with group R, subjects in group P received a higher dose of fentanyl in PCA $(1041.23 \pm 145.94 \mathrm{mcg}$ versus $1102.99 \pm 195.97, P<0.001$; Table 1). In addition, subjects in group $\mathrm{P}$ showed a lower incidence of receiving premedication drugs (365 [63.9\%] versus 69 [38.5\%], $P<0.001$; Table 1), $\mathrm{N}_{2} \mathrm{O}$ (481 [84.2\%] versus 130 [72.6\%], $P<0.001$; Table 1), preintubation opioids (425 [74.4\%] versus 111 [62.0\%], $P=0.001$; Table 1 ), and Acupan (289 [50.6\%] versus 54 [30.2\%], $P<0.001$; Table 1).

All variables including pain VAS, nausea NRS, CR, amount of vomiting, dizziness, and headache on POD 0 and POD 1 showed no significant differences between group $R$ and group P (Table 2).

3.2. Ramosetron versus Palonosetron according to Propensity Score Analysis. After the propensity score analysis, 152 patients remained (Figure 1). All 14 confounding variables had acceptable standardized difference scores $(<20 \%)$ indicating that the matching procedure was efficient in creating balance between the two groups. After adjusting the propensity score analysis, the overall incidence of PONV at POD 0 was lower in group $\mathrm{R}$ compared to group P (26.9\% versus $36.8 \% ; P=0.043)$. The nausea NRS on POD 0 was reported as higher in group $\mathrm{P}$ compared to group $\mathrm{R}(0.15 \pm 0.44$ versus $0.34 \pm 0.79 ; P=0.012$ ). Also, $\mathrm{CR}$ status on POD 0 was significantly higher in group R compared to group P (73\% versus $63.2 \% ; P=0.043)$. However, no significant difference was observed in nausea NRS and CR status on POD 1, pain VAS, rescue antiemetics, amount of vomiting, dizziness, or headache on POD 1 and POD 2 between group R and group $\mathrm{P}$ (Table 3).

\section{Discussion}

The etiology of PONV remains unclear but involves anesthetic, surgical, patient, and PCA factors. Well-known patient specific risk factors include female gender, nonsmoking, and history of motion sickness or PONV, whereas nonspecific factors involve the use of postoperative opioids and the type of surgery performed, such as laparoscopy [11, 12]. In our present study, all patients exhibited at least three risk factors including female gender, postoperative opioid use, and laparoscopy. The results have shown that ramosetron was more effective in the prevention of postoperative nausea compared to palonosetron. However, there was no significant difference in the prevention of vomiting between both drugs.

The area postrema, or vomiting center, controls and coordinates nausea and vomiting and is located in the lateral reticular formation of the medulla. This center receives various inputs from receptors in the gastrointestinal tract, peripheral pain receptors, the nucleus solitaries, the vestibular system, the cerebral cortex, and the chemoreceptor trigger zone [13]. The high incidence of PONV after laparoscopy is explained by the compression of the gastrointestinal mucosa by the surgical pneumoperitoneum which may induce intestinal 
TABLE 1: Patient characteristics in total and matched cohorts.

\begin{tabular}{|c|c|c|c|c|c|c|c|c|}
\hline \multirow[b]{2}{*}{ Characteristic } & \multicolumn{4}{|c|}{ Total set } & \multicolumn{4}{|c|}{ Matched set } \\
\hline & $\begin{array}{c}\text { Group R } \\
(n=589)\end{array}$ & $\begin{array}{l}\text { Group P } \\
(n=166)\end{array}$ & STD (\%) & $P$ value & $\begin{array}{c}\text { Group R } \\
(n=152)\end{array}$ & $\begin{array}{c}\text { Group P } \\
(n=152)\end{array}$ & STD (\%) & $\begin{array}{c}P \\
\text { value }\end{array}$ \\
\hline Age & $42.68 \pm 19.96$ & $39.64 \pm 12.66$ & -16.34 & 0.056 & $39.95 \pm 12.82$ & $39.36 \pm 14.42$ & -4.32 & 0.675 \\
\hline Height & $159.14 \pm 6.93$ & $159.68 \pm 9.21$ & 7.21 & 0.418 & $159.23 \pm 5.91$ & $159.45 \pm 8.32$ & 3.05 & 0.735 \\
\hline Weight & $57.66 \pm 9.15$ & $57.46 \pm 9.74$ & -2.15 & 0.810 & $57.60 \pm 9.03$ & $57.51 \pm 8.32$ & -1.04 & 0.923 \\
\hline OP time & $139.21 \pm 111.01$ & $156.36 \pm 165.98$ & 13.7 & 0.113 & $136.62 \pm 93.18$ & $152.51 \pm 165.53$ & 11.83 & 0.263 \\
\hline PCA fentanyl (mcg) & $1041.23 \pm 145.94$ & $1102.99 \pm 195.97$ & 39.02 & $<0.001$ & $1064.63 \pm 191.24$ & $1081.55 \pm 191.49$ & 8.84 & 0.412 \\
\hline Smoking & $40(7.0)$ & $14(7.8)$ & 10.81 & 0.712 & $8(5.3)$ & $8(5.3)$ & 0 & 1.000 \\
\hline PONV history & $30(5.3)$ & $13(7.3)$ & 31.75 & 0.313 & $11(7.2)$ & $10(6.6)$ & -8.33 & 1.000 \\
\hline Premedication & $365(63.9)$ & $69(38.5)$ & 49.61 & $<0.001$ & $69(45.4)$ & $63(41.4)$ & -8.81 & 0.135 \\
\hline Sevoflurane & $203(35.6)$ & $72(40.2)$ & 12.14 & 0.258 & $56(36.8)$ & $65(42.8)$ & 16.30 & 0.336 \\
\hline Desflurane & $368(64.4)$ & $107(59.8)$ & 7.41 & 0.258 & $96(63.2)$ & $97(63.8)$ & 0.95 & 0.981 \\
\hline $\mathrm{N}_{2} \mathrm{O}$ & $481(84.2)$ & $130(72.6)$ & 14.80 & $<0.001$ & $122(80.3)$ & $118(77.6)$ & -3.36 & 0.418 \\
\hline Preintubation opioid & $425(74.4)$ & $111(62.0)$ & 18.18 & 0.001 & $101(66.4)$ & $99(65.1)$ & -1.96 & 0.838 \\
\hline Remifentanil & $42(7.4)$ & $15(8.4)$ & 12.66 & 0.652 & $15(9.9)$ & $12(7.9)$ & -20.20 & 0.664 \\
\hline Acupan & $289(50.6)$ & $54(30.2)$ & 50.50 & $<0.001$ & $58(38.2)$ & $52(34.2)$ & -10.47 & 0.504 \\
\hline
\end{tabular}

Values are expressed as mean \pm SD, absolute number (percentages), or absolute number. OP: operation, STD: standardized difference, PONV: postoperative nausea and vomiting, and PCA: patient-controlled analgesia.

TABLE 2: Perioperative variables before matching.

\begin{tabular}{|c|c|c|c|c|}
\hline & $\begin{array}{c}\text { Group R } \\
(n=589)\end{array}$ & $\begin{array}{c}\text { Group S } \\
(n=166)\end{array}$ & STD (\%) & $P$ value \\
\hline Pain VAS at day 0 & $6.29 \pm 1.93$ & $6.23 \pm 172$ & -0.07 & 0.346 \\
\hline Pain VAS at day 1 & $3.07 \pm 1.55$ & $2.86 \pm 1.37$ & -13.89 & 0.108 \\
\hline Nausea NRS at day 0 & $0.25 \pm 0.65$ & $0.35 \pm 0.82$ & 14.48 & 0.111 \\
\hline Nausea NRS at day 1 & $0.06 \pm 0.27$ & $0.03 \pm 0.26$ & -11.2 & 0.212 \\
\hline Rescue antiemetics at day 0 & $75(13.1)$ & $28(15.6)$ & 17.42 & 0.395 \\
\hline Rescue antiemetics at day 1 & $33(5.6)$ & $10(6.0)$ & 6.90 & 0.835 \\
\hline PONV at day 0 & $169(28.7)$ & $59(35.5)$ & -10.01 & 0.090 \\
\hline PONV at day 1 & $67(11.4)$ & $23(13.8)$ & 2.86 & 0.651 \\
\hline CR at day 0 & $420(71.3)$ & $107(64.5)$ & 10.01 & 0.090 \\
\hline CR at day 1 & $522(88.6)$ & $143(86.1)$ & -2.86 & 0.651 \\
\hline Number of vomiting instances at day 0 & $0.05 \pm 0.43$ & $0.03 \pm 0.26$ & -5.01 & 0.544 \\
\hline Number of vomiting instances at day 1 & $0.00 \pm 0.59$ & $0.01 \pm 0.09$ & 1.91 & 0.429 \\
\hline Dizziness at day 0 & $14(2.5)$ & $2(1.1)$ & 77.78 & 0.382 \\
\hline Dizziness at day 1 & $13(2.3)$ & $3(1.7)$ & 30 & 0.774 \\
\hline Headache at day 0 & $1(0.2)$ & $1(0.6)$ & 100 & 0.421 \\
\hline Headache at day 1 & $3(0.5)$ & $0(0.0)$ & 200 & 1.000 \\
\hline
\end{tabular}

Values are expressed as mean $\pm \mathrm{SD}$, absolute number (percentages), or absolute number. STD: standardized difference, VAS: visual analogue scale, NRS: numerical rating scale, and CR: complete responder.

ischemia and thus trigger a serotonin release leading to PONV [14]. The central action of carbon dioxide $\left(\mathrm{CO}_{2}\right)$, stretching of the peritoneum and diaphragm, and increased blood pressure in the peritoneal cavity after $\mathrm{CO}_{2}$ insufflation are considered to provoke PONV by reducing blood flow $[15,16]$. Therefore, a variety of serotonin receptor (5-HT3) antagonists with a similar mechanism (selective or competitive binding to 5-HT3 receptors) have been used to manage
PONV [17]. In this study, we compared two antiemetics, ramosetron and palonosetron, for the prevention of PONV after gynecological laparoscopy. Similar to the results of previous studies, ramosetron was superior to palonosetron in preventing postoperative nausea $[13,18]$. However, discrepancies exist in a number of studies that compared ramosetron and palonosetron. The studies of Lee showed no significant differences between ramosetron and palonosetron in the 
TABLE 3: Perioperative variables after matching.

\begin{tabular}{lccc}
\hline & $\begin{array}{c}\text { Group R } \\
(n=152)\end{array}$ & $\begin{array}{c}\text { Group P } \\
(n=152)\end{array}$ & STD (\%) \\
\hline Pain VAS at day 0 & $6.17 \pm 1.87$ & $6.17 \pm 1.79$ & 0 \\
Pain VAS at day 1 & $2.99 \pm 1.58$ & $2.86 \pm 1.41$ & -8.68 \\
Nausea NRS at day 0 & $0.15 \pm 0.44$ & 29.71 & 0.443 \\
Nausea NRS at day 1 & $0.05 \pm 0.25$ & $0.34 \pm 0.79$ & $0.012^{*}$ \\
Rescue antiemetics at day 0 & $16(10.5)$ & $0.09 \pm 0.35$ & 0.275 \\
Rescue antiemetics at day 1 & $9(5.9)$ & $27(17.8)$ & 0.15 \\
PONV at day 0 & $41(26.9)$ & $8(5.3)$ & -10.17 \\
PONV at day 1 & $15(9.8)$ & $56(36.8)$ & 13.42 \\
CR at day 0 & $111(73.0)$ & $21(13.8)$ & 0.803 \\
CR at day 1 & $137(90.1)$ & $96(63.2)$ & -13.42 \\
Number of vomiting instances at day 0 & $0.03 \pm 0.27$ & $131(86.2)$ & -4.33 \\
Number of vomiting instances at day 1 & $0.00 \pm 0.00$ & 0.287 \\
Dizziness at day 0 & $2(1.3)$ & $0.03 \pm 0.27$ & $0.043^{*}$ \\
Dizziness at day 1 & $2(1.3)$ & $0.01 \pm 0.08$ & 0.287 \\
Headache at day 0 & $0(0.0)$ & $0(0.0)$ & 1.000 \\
Headache at day 1 & $0(0.0)$ & $0(0.0)$ & 0.319 \\
\hline
\end{tabular}

Values are expressed as mean \pm SD, absolute number (percentages), or absolute number. STD: standardized difference, VAS: visual analogue scale, NRS: numerical rating scale, and CR: complete responder. ${ }^{*} \mathrm{P}<0.05$ between group comparison.

incidence of PONV in patients who underwent gynecological laparoscopy $[19,20]$.

Our study showed a significant difference between ramosetron and palonosetron for overall incidence of PONV and CR rate on POD 0. Also, postoperative nausea NRS scores on POD 0 were significantly higher in the ramosetron group than in the palonosetron group on POD 0 . However, there are a number of studies which reported pharmacologic difference between the ramosetron and palonosetron. In the study of Swaika, ramosetron was more effective than palonosetron in the early postoperative period $(0-2 \mathrm{~h})$ [13]. But, in the time periods of $2-6 \mathrm{~h}$ and $6-24 \mathrm{~h}$, there was no statistically significant difference between both groups [13]. Therefore, further studies would be needed to find the pharmacologic influence in this result.

There were limitations in this study. First, although the dose of antiemetics administered may have affected the results, we were unable to evaluate the dose of antiemetics administered. Second, as previously stated, we considered the possibility of missing data due to the retrospective design and the extended time span between the first and the last included case. Finally, this was a single center study in Korea; generalized results may not be applicable to patients in other countries. In spite of the retrospective design, we highlight the strengths of our study by noting the substantial amount of clinical data that was analyzed and the performance of propensity score matching to avoid confounding selection bias.

In conclusion, ramosetron has shown greater efficacy for the prevention of PONV at POD 0 in comparison to palonosetron in patients that underwent laparoscopic gynecological surgery.

\section{Competing Interests}

No authors have competing interests to declare.

\section{Acknowledgments}

This research was supported by the Basic Science Research Program through the National Research Foundation (NRF) of Korea, funded by the Ministry of Education, Science and Technology (NRF-2015R1A2A01005153).

\section{References}

[1] S. J. Dolin, J. N. Cashman, and J. M. Bland, "Effectiveness of acute postoperative pain management: I. Evidence from published data," British Journal of Anaesthesia, vol. 89, no. 3, pp. 409-423, 2002.

[2] J. Golembiewski, E. Chernin, and T. Chopra, "Prevention and treatment of postoperative nausea and vomiting," American Journal of Health-System Pharmacy, vol. 62, no. 12, pp. 12471262, 2005.

[3] H. Eriksson and K. Korttila, "Recovery profile after desflurane with or without ondansetron compared with propofol in patients undergoing outpatient gynecological laparoscopy," Anesthesia and Analgesia, vol. 82, no. 3, pp. 533-538, 1996.

[4] A. S. Habib and T. J. Gan, "Evidence-based management of postoperative nausea and vomiting: a review," Canadian Journal of Anesthesia, vol. 51, no. 4, pp. 326-341, 2004.

[5] Y.-K. Song and C. Lee, "Effects of ramosetron and dexamethasone on postoperative nausea, vomiting, pain, and shivering in female patients undergoing thyroid surgery," Journal of Anesthesia, vol. 27, no. 1, pp. 29-34, 2013. 
[6] S.-Y. Yang, N.-H. Jun, Y.-S. Choi et al., "Efficacy of dexamethasone added to ramosetron for preventing postoperative nausea and vomiting in highly susceptible patients following spine surgery," Korean Journal of Anesthesiology, vol. 62, no. 3, pp. 260-265, 2012.

[7] J. W. Park, J. W. Jun, Y. H. Lim et al., "The comparative study to evaluate the effect of palonosetron monotherapy versus palonosetron with dexamethasone combination therapy for prevention of postoperative nausea and vomiting," Korean Journal of Anesthesiology, vol. 63, no. 4, pp. 334-339, 2012.

[8] S. M. Perkins, W. Tu, M. G. Underhill, X.-H. Zhou, and M. D. Murray, "The use of propensity scores in pharmacoepidemiologic research," Pharmacoepidemiology and Drug Safety, vol. 9, no. 2, pp. 93-101, 2000.

[9] M. A. Brookhart, S. Schneeweiss, K. J. Rothman, R. J. Glynn, J. Avorn, and T. Stürmer, "Variable selection for propensity score models," American Journal of Epidemiology, vol. 163, no. 12, pp. 1149-1156, 2006.

[10] P. C. Austin, "A critical appraisal of propensity-score matching in the medical literature between 1996 and 2003," Statistics in Medicine, vol. 27, no. 12, pp. 2037-2049, 2008.

[11] C. C. Apfel and N. Roewer, "Postoperative nausea and vomiting," Anaesthesist, vol. 53, no. 4, pp. 377-392, 2004.

[12] T. J. Gan, T. Meyer, C. C. Apfel et al., "Consensus guidelines for managing postoperative nausea and vomiting," Anesthesia and Analgesia, vol. 97, no. 1, pp. 62-71, 2003.

[13] A. Pal, D. Saha, S. Swaika, S. Chatterjee, and N. Dawar, "Ondansetron, ramosetron, or palonosetron: which is a better choice of antiemetic to prevent postoperative nausea and vomiting in patients undergoing laparoscopic cholecystectomy?" Anesthesia: Essays and Researches, vol. 5, no. 2, pp. 182-186, 2011.

[14] V. Goll, O. Akça, R. Greif et al., "Ondansetron is no more effective than supplemental intraoperative oxygen for prevention of postoperative nausea and vomiting," Anesthesia and Analgesia, vol. 92, no. 1, pp. 112-117, 2001.

[15] L. N. Diebel, S. A. Dulchavsky, and R. F. Wilson, "Effect of increased intra-abdominal pressure on mesenteric arterial and intestinal mucosal blood flow," Journal of Trauma - Injury, Infection and Critical Care, vol. 33, no. 1, pp. 45-49, 1992.

[16] K. Leksowski, P. Peryga, and R. Szyca, "Ondansetron, metoclopramid, dexamethason, and their combinations compared for the prevention of postoperative nausea and vomiting in patients undergoing laparoscopic cholecystectomy: a prospective randomized study," Surgical Endoscopy and Other Interventional Techniques, vol. 20, no. 6, pp. 878-882, 2006.

[17] L. H. J. Eberhart, S. Frank, H. Lange et al., "Systematic review on the recurrence of postoperative nausea and vomiting after a first episode in the recovery room-implications for the treatment of PONV and related clinical trials," BMC Anesthesiology, vol. 6, article 14, 2006.

[18] S. I. Kim, S. C. Kim, Y. H. Baek, S. Y. Ok, and S. H. Kim, "Comparison of ramosetron with ondansetron for prevention of postoperative nausea and vomiting in patients undergoing gynaecological surgery," British Journal of Anaesthesia, vol. 103, no. 4, pp. 549-553, 2009.

[19] W.-S. Lee, K.-B. Lee, S. Lim, and Y. G. Chang, "Comparison of palonosetron, granisetron, and ramosetron for the prevention of postoperative nausea and vomiting after laparoscopic gynecologic surgery: a prospective randomized trial," $B M C$ Anesthesiology, vol. 15, no. 1, article 121, 2015.
[20] Y. S. Shin and A. Kim, "Comparison of palonosetron with ramosetron in prevention of postoperative nausea and vomiting in patients undergoing gynecological laparoscopic surgery and receiving postoperative intravenous patient-controlled analgesia: 9AP5-3," European Journal of Anaesthesiology (EJA), vol. 28, p. 139, 2011. 


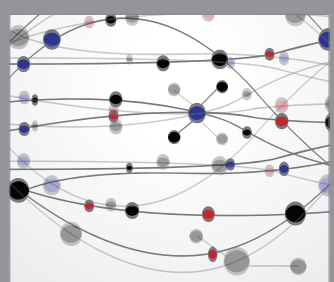

The Scientific World Journal
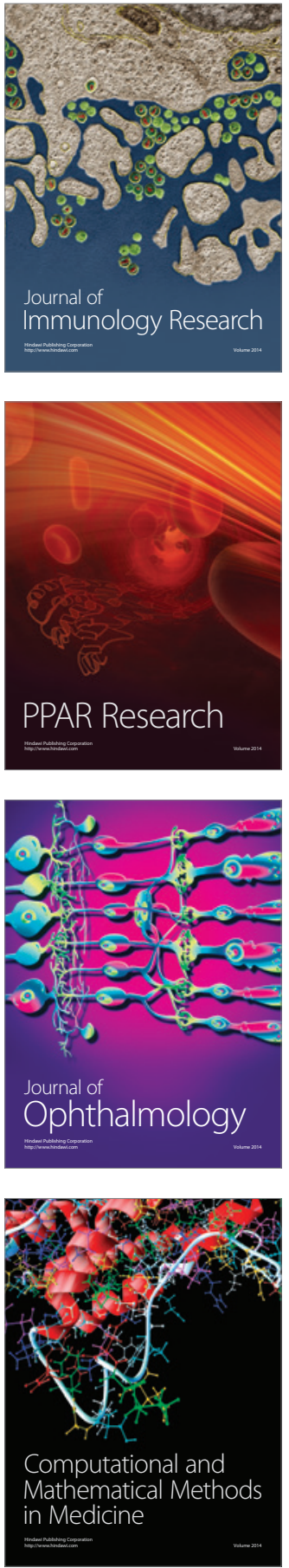

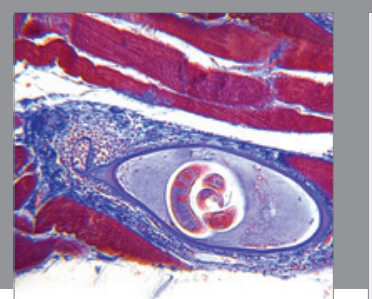

Gastroenterology Research and Practice
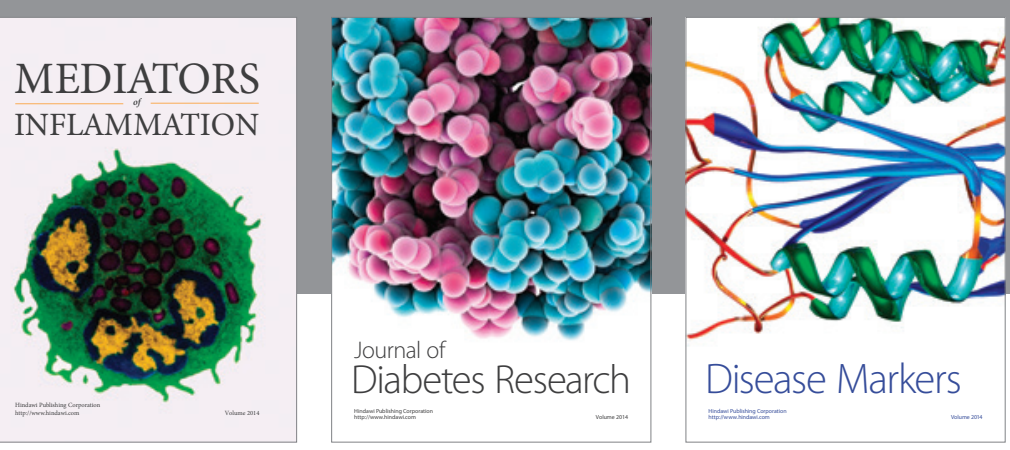

Disease Markers

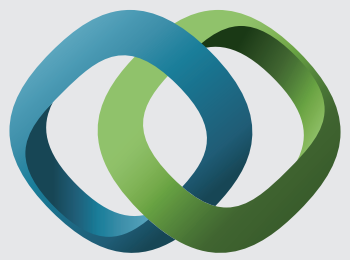

\section{Hindawi}

Submit your manuscripts at

https://www.hindawi.com
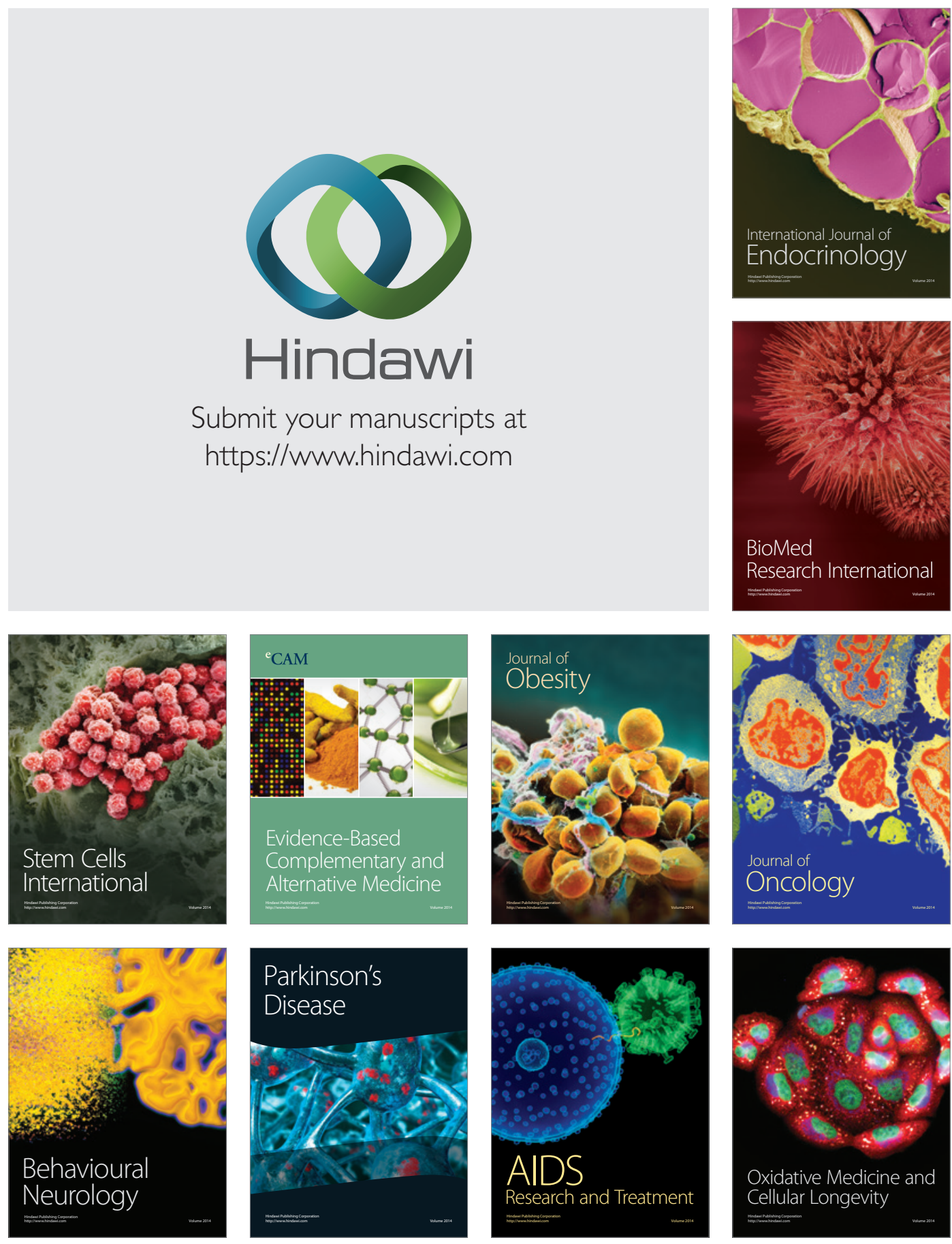